\title{
ITALIAN RAILWAY STATIONS HERITAGE
}

\author{
EMILIA GARDA, ALBERTO GERBINO \& MARIKA MANGOSIO \\ Politecnico di Torino, Italy
}

\begin{abstract}
The railway station represents the most advanced product of the architectural and technical culture of the age in which it was built. Nevertheless, the heritage of the railway stations can be considered as rather fragile. The knowledge of the construction history of these building is important in order to preserve the compositive values and the innovative technical solutions embedded in the building itself, particularly in case of a restoration or a complete renewal. The article aims to illustrate how the Italian railway stations have been designed and built throughout the years. The study focuses first of all on the railway stations which marked the beginning of the railway lines such as Torino Porta Nuova and Milano Centrale, which can be considered an example of the splendour achieved by the railway stations before the Second World War. Secondly the study analyses the new railway stations which are the starting point for the high speed railway lines such as Torino Porta Susa and Roma Tiburtina. The article dwells not only on the evolution of the architectonical language and of the layout of the station, but it focuses also on the structural scheme of the roofing solutions, which in many cases represent the true element of modernity.
\end{abstract}

Keywords: conservation, passengers' building, railway roofs, railway stations, renewal, restoration.

\section{INTRODUCTION}

Between the 17th and 18th centuries, Europe saw the birth of the 'stage coach service', a service used for transporting both post and passengers with vehicles with two or more wheels pulled by horses along carriage roads. The slow speed of the transport, which on flatlands could reach approximately 8 kilometres an hour but in the mountains could manage just 4 kilometres an hour, meant travel times were long -25 hours from Turin to Genoa - and the need for 'stations' to change horses located at variable intervals depending on the difficulty of the roads and the presence of towns and villages.

The process of technological innovation that accompanied the Industrial Revolution marked a moment of great change in passenger transport: in fact, it was only thanks to the invention of the steam engine that we saw the arrival of the train, all infrastructures linked thereto, railways and stations. The first railway line in history built for the transport of goods and people linked the mining area of Darlington with Stockton in the county of Durham in England. This line was inaugurated in 1825 by a convoy pulled by Locomotion 1, created and designed by George Stephenson, at an average speed of 10 kilometres an hour. Italy would have to wait until 3rd October 1839 for its first railway line, which connected Naples to Granatello station in Portici for a total length of 7,640 metres and was created by the French engineer Bayard de la Vingtrie.

The subsequent organization of the railway line once more includes - with all relevant precautions - the stations system. Railway architecture developed further with the advent of the railway track, continuing its original representation of the perfect union of art and engineering.

The station is basically made up of two parts: the passengers building, the compositive solutions of which reflect the architectural conception of the time, and a large covered space for the tracks, representing the maximum expression of engineering. Its function is to welcome travellers as they arrive and depart and also accommodate the loading and unloading of 
goods. It also includes all the functional areas required for goods loading and unloading management, the warehouses and the technical rooms for maintenance activities. In the initial phase of railway development, terminals represented the main kind of station, those stations where the tracks stop and can go no further, unlike transit stations in which the tracks are not interrupted and the trains may continue their journey.

The railway station soon took on the role of modern gateway to the city [1].

\section{STATIONS IN THE NEW KINGDOM OF ITALY}

Following the Unification of Italy, the railway station becomes one of the main urban architectural hubs to contribute to the formation of a new national identity [2]. Like all the large stations in Europe at the time, they are characterized by the monumentality of the volumetric and compositive solutions and for their insertion within the urban fabric through a large open space and for their significant impact on the urban development of the city. The stations of Torino Porta Nuova and Milano Centrale are two important examples.

\subsection{A station for the new capital city of the Kingdom of Italy}

Torino Porta Nuova was one of the first railway stations built in Italy, born as the departure point for the railway line to Genoa. In 1845, Carlo Alberto commissioned the project to the Belgian engineer Maus, but due to heated arguments on the definitive system and the subsequent political events the project was abandoned. The situation improved in 1875 thanks only to the interest shown by Camillo Cavour who was much in favour of the expansion of railway transport. In 1860, the Director General of the Railway, lawyer Bartolomeo Bona, commissioned engineer Alessandro Mazzucchetti to draw up the definitive project for the Porta Nuova station which was then officially approved by the Parliament of the Kingdom of Italy the next year [3].

In 1864, Mazzucchetti left the management of works to dedicate his time to his own employment and was succeeded by his former collaborator, engineer Angelo Gilodi. Works were completed in 1868 for a total cost of 3,400,000 lire, 25\% more than the original quote: one of the reasons for this was the finding of a stretch of tunnels from the ancient fortifications during excavations to build the foundations. This meant that the excavations had to be dug a further 8 metres beyond than planned, but also allowed for the building of large underground rooms used for storage and technical areas, which today in part are home to the tube station.

In Turin's station project the passengers' building is organized based on the planning experience of previous years throughout Europe and in particular in England, where the passengers' building was built separate from the buildings reserved for goods and management and maintenance services which were located in a more isolated area.

Mazzucchetti's passengers' building clearly distinguishes between the departure and arrival services in both the functional and provision aspects. The architect placed the seven central tracks with their relative platforms 6 metres from the glass facade opposite piazza Carlo Felice, meaning the trains could be seen from the garden opposite, and placed two rectangular buildings to the sides - one for departures on the side of via Nizza, and the other for arrivals coming off of via Sacchi. Each one had a square in front of it (Fig. 1).

Each of the two passengers' buildings also has an arcade towards the exterior which is interconnected by a 7-metre-wide portico which faces onto piazza Carlo Felice.

In the arrivals building there is a central exit passage for passengers, a waiting room, luggage areas, a post office and a tunnel for the trains. In the departure area there is a spacious 


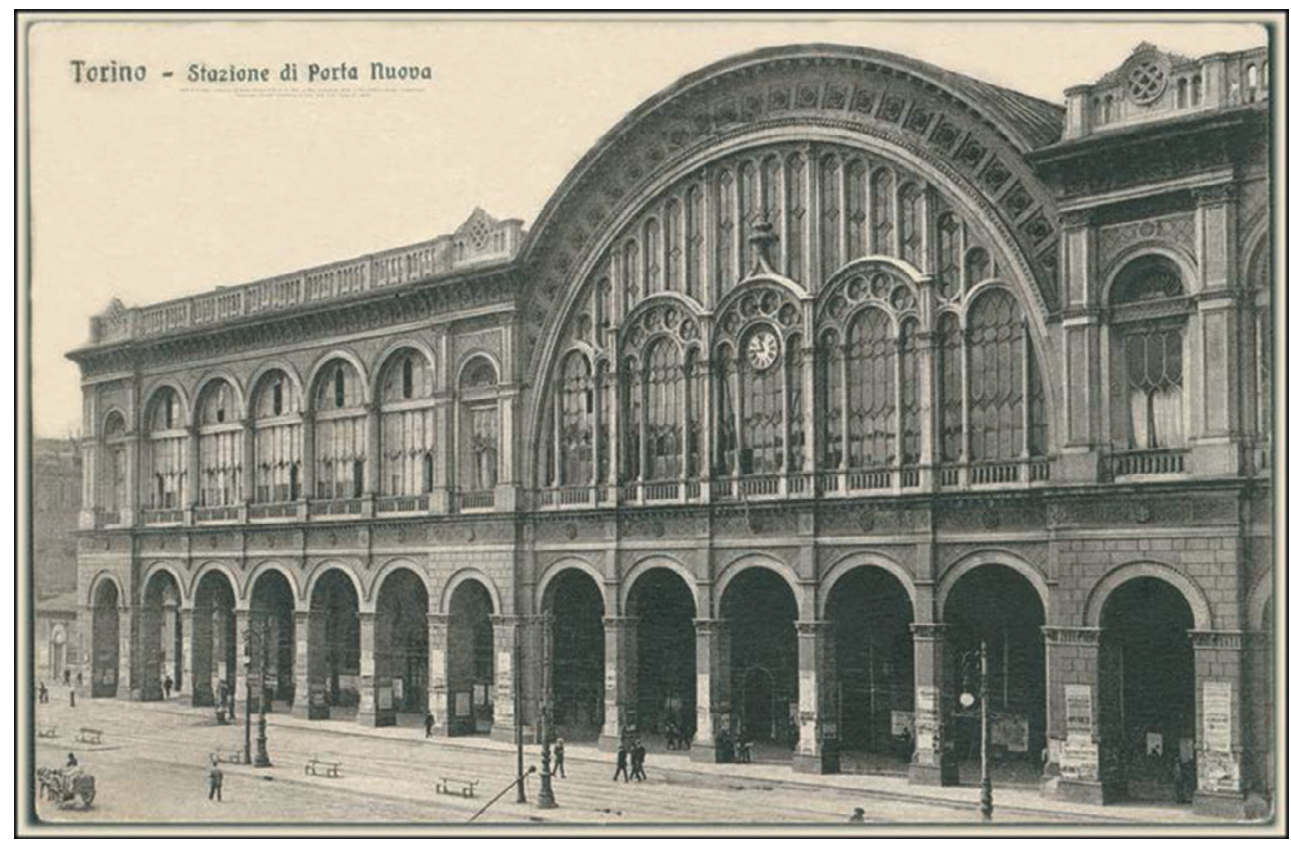

Figure 1: Torino Porta Nuova, the main façade designed by architect Carlo Ceppi. (www.lineetramtorino.com/CartolineB.html)

ticket area decorated with columns, stuccos and frescoes and three waiting rooms, one for each of the three railway classes. The main facade overlooking piazza Carlo Felice was mainly designed by architect Carlo Ceppi. It has a double order of arches on the top and bottom and a central semi-circular 30-metre window surrounded by a ring-shaped frame which stretches as high as the extrados of the roof.

Mazzucchetti chose to cover the tracks with a barrel vault ceiling supported by iron arches set into the brickwork pillars, taking inspiration from the ceiling of the Palace of Industry in Paris built in 1855. The use of iron - which was still being experimented with at the time - arose from the need for a lighter structure and to thus give the overall building 'solidity united with elegance'. The roof of Porta Nuova was a technologically innovative solution for the times. The ceiling stretches up to a height of 30 metres above the iron and is made up of a grid of 21 arches 7 metres apart and interconnected by transversal elements made up of circular bars. Mazzucchetti even designed a kind of scaffolding to assemble the arches covering the entire length of the roof, which allowed assembly to continue without interrupting railway traffic.

This magnificent example of structural engineering has been lost as it was dismantled in 1941 so the material could be used in the war effort. The departures building on via Nizza was also seriously damaged in 1942 during the RAF bombings (Fig. 2).

\subsection{The new Milano Centrale station}

At the beginning of the 20th century the central station of Milan, built in 1857, was found to be unsuitable to accommodate the new levels of railway traffic. For the project for the new Milano Centrale building tenders were first called in 1906 which was left incomplete, 


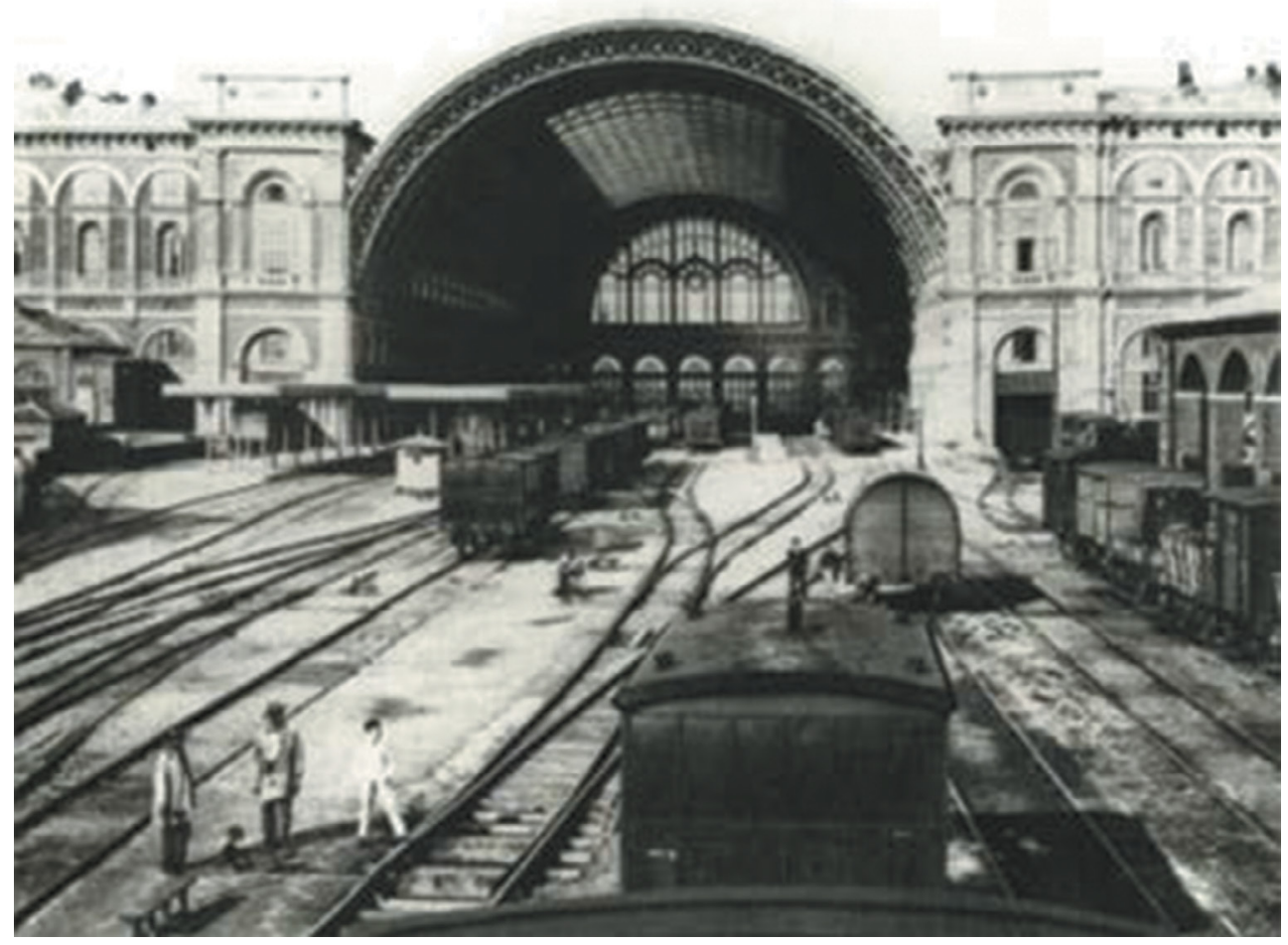

Figure 2: Torino Porta Nuova, the passengers' building and the iron arches of the roof. (L. Ballatore, Storia delle ferrovie in Piemonte, Il Punto: Torino, p. 151, 1996)

and then again in 1912. Works only started in 1925 and the new Central Station was opened officially in 1931 [4] (Fig. 3).

The building plan is rather simple in form, made up of two overlapping rectangles that extend out perpendicular to the tracks. The most exterior area was reserved for the covered entrance hall to the passengers' building next to the roof, which is characterized by its wide range of different interiors (Fig. 4).

The monumentality of the sizes, the compositive solutions and the decorative elements of the passengers' building designed by Ulisse Stacchini reflects the symbolic value that the company gave to the construction of stations when the railway system was enjoying its epochal apex. The exemplarity of Milano Centrale also consists in how it represents a sort of tangible manifesto of the level of excellence reached by the scientific and engineering culture of the time. The theoretical progress made in the science of construction, mainly due to Carlo Alberto Castigliano and Luigi Cremona, led to the determination of new assembly techniques in metal structural work and the patent of reinforced concrete and made it possible to construct buildings with steel and reinforced concrete load-bearing skeletons of increasing size.

At the time the Milano Centrale project was drafted, metal covers over the tracks started being gradually replaced by cantilever roofs as the former no longer satisfied the requirements of modern railway architecture, such as the possibility to expand and renew the squares, to reduce the fumes from the locomotives and, last but not least, to reduce sound pollution. 


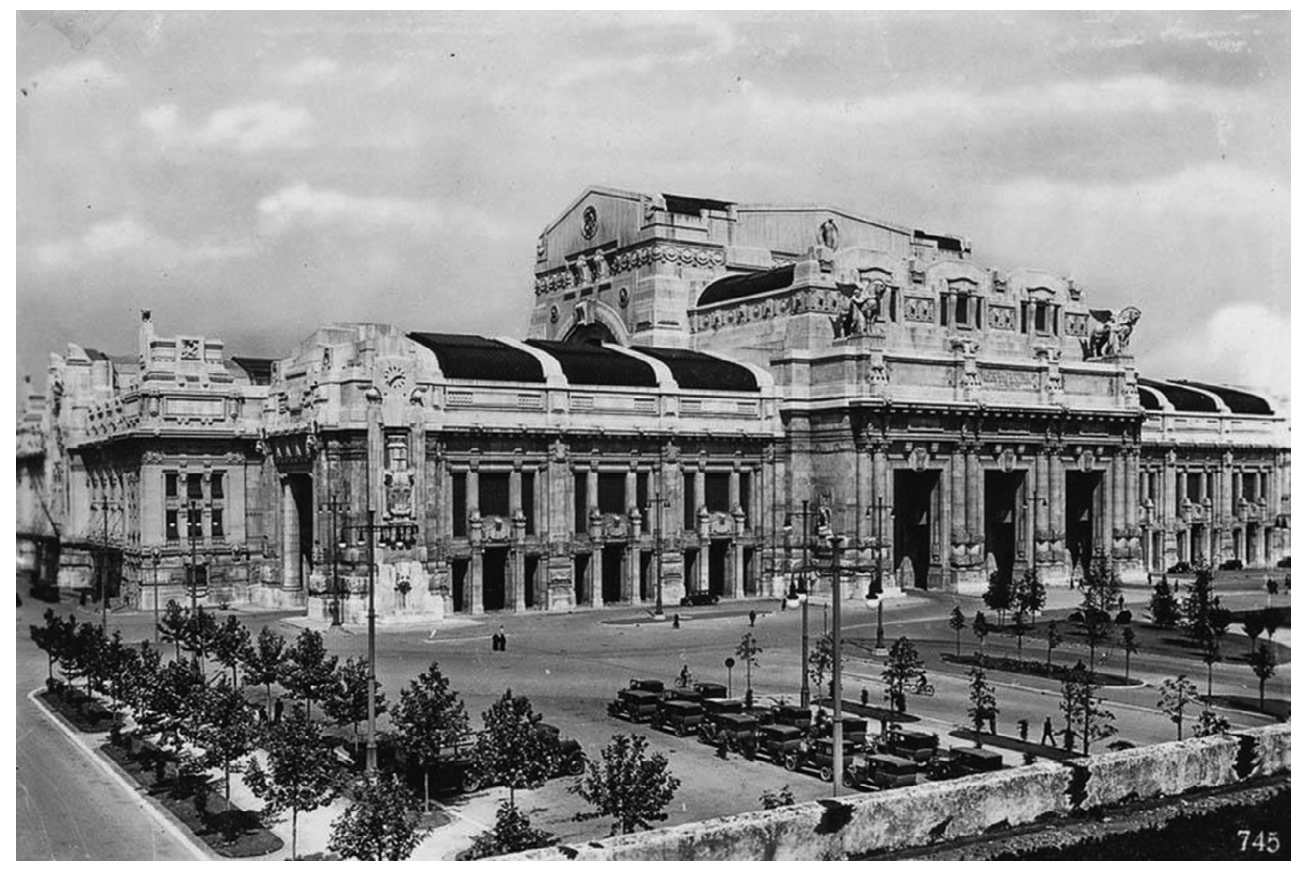

Figure 3: Milano Centrale, the monumental passengers' building designed by Ulisse Stacchini. (mi4345.it/stazione-di-milano-centrale/)

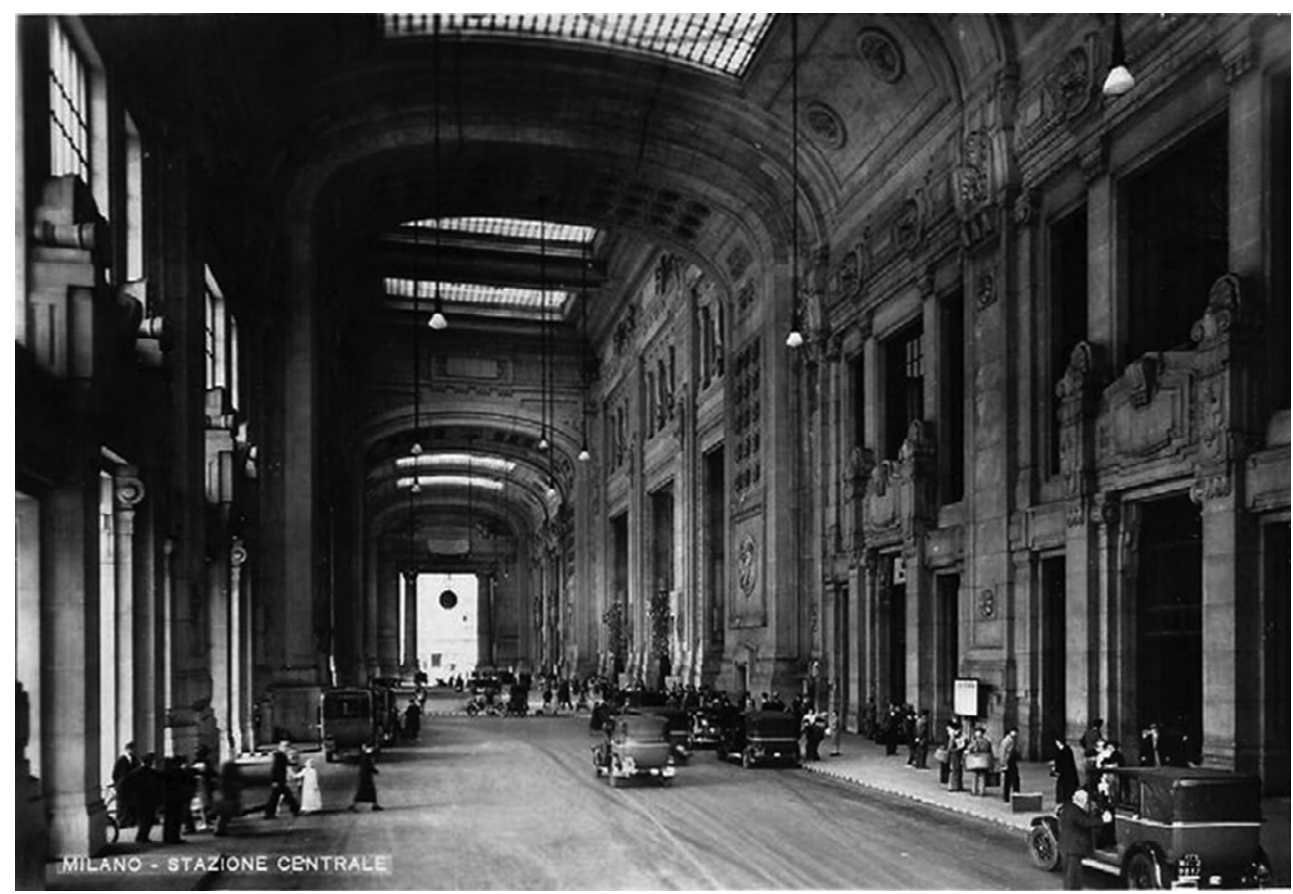

Figure 4: Milano Centrale, the coach gallery. (www.skyscrapercity.com) 
It is interesting to see how in 1914, almost 10 years before the definitive projects were drawn up for the Milan station, Boccioni wrote in the first Manifesto of Futuristic Architecture: 'The large railway roofs that were so distantly related to the grandiose nave of the cathedral area replaced by cantilever roofs that are adequate and necessary to cover trains in arrival and departure'.

The designers' decision to opt for a metallic roof was dictated by reasons of a distributive nature. The tracks are alternated in couples by 9-metre-wide platforms, which in the initial previsions were to accommodate the flow of passengers, luggage, goods and post, and to be integrated by a system of goods lifts and underground tunnels, to reduce interference between the flow of passengers and various services. To further divide the flow of people from that of the trolleys, the designers included a secondary platform between each pair of tracks used only for trolleys. This new platform however meant that the designers had to reduce the width of the platform used by the passengers and therefore do without the cantilever roofs, the support of which would have required too much space.

The imposing metal roof, designed by engineer Alberto Fava, covers an area of approximately 182 metres in width and 340 metres in length and is made up of five round arches which gradually decrease in size from the interior to the exterior. The metal structure, constructed using the hot riveting technique, was created by the Officine Savigliano in Turin. The central bay covers a span of 72 metres and is 33.5 metres in height. The static plan of the arcade is that of a three-hinged arch.

\section{RENEWAL, CRISIS AND THE REPRISAL OF THE RAILWAY THANKS TO THE HIGH SPEED SYSTEM}

Between the 1920s and the Second World War there was a renewal in railway architecture, one of the main protagonists of which was Angiolo Mazzoni. Mazzoni proposed advanced typological solutions that were inflected with a strongly innovative language. The events surrounding the national bid for tenders for the passengers' building of the $\mathrm{S}$. Maria Novella station (1932-1933) were emblematic [5].

The train remained the main mode of transport until the end of the Second World War. In the post-war years railway transport underwent a moment of great crisis due to the domineering ascent of road transport and air transport. In industrialized countries, the 1950s saw a great progress in road motorization due to lower production costs - possible thanks to new technology, the creation of motorways and improvement in existing roads - which made train travel less competitive for medium and short journeys. Airplanes were the most competitive for long-haul journeys.

Faced with an initial evident backwardness and inefficiency of the national railway system, costs were reduced, thus abolishing lesser-used tracks, rather than implementing effective modernization measures.

This gradual decline was interrupted only in 1964, when Japan opened its Tokaido, a new high-speed passenger railway line between Tokyo and Osaka, for which the Shinkansen was specially created - an electric train that could travel at speeds of up to 200 kilometres an hour. This marked the birth of high speed rail travel, a new railway network that - thanks to the increase of minimum curve ratios, new methods of electrification and especially created trains - allowed high-speed transport of passengers between the main urban centres that could compete with air transport.

The creation of a high speed railway network inevitably led to an adjustment of railway architecture in line with the new demands of transport and circulation. The train must be able 
to stop at stations only for the minimum time necessary for passengers to alight and descend from the train and must be able to depart immediately for the next station in the quickest time possible. Contrary to the 19th century belief that gave most importance to terminals, high speed trains put them at risk of being completely cut out from this system unless they represented a full terminal for the railway line. Thereby the need arises for the modernization of old secondary stations, for example Torino Porta Susa and Roma Tiburtina, and for the integration of the network through the construction of new buildings, such as the stations of Firenze Belfiore and Napoli Afragola [6].

The new railway architecture is characterized by state-of-the-art compositive and technological solutions and by a distributive conception that privileges the intermodality of transport.

\subsection{The new life of Torino Porta Susa}

The transformation of the Torino Porta Susa station was exclusively focussed on the plan drafted for the high speed and high capacity railway network with the aim to provide rapid connections with Italian cities, Milan in particular, but also with the rest of Europe, in particular with France thanks to the TAV line. The new Porta Susa, officially opened in 2013, was Italy's first high speed station on the Paris-Rome line [7] (Fig. 5).

In 2001 tenders were called to create the new passengers' building with funding of 79 million euro. The AREP Group (Jean-Marie Duthilleul and Etienne Tricaud) in collaboration with Silvio D'Ascia and Agostino Magnaghi won the bid out of 55 proposals made. The initial project only involved a partial burial of the railway track between Porta Susa and the Torino Lingotto station. Its subsequent integration into an important operation of urban

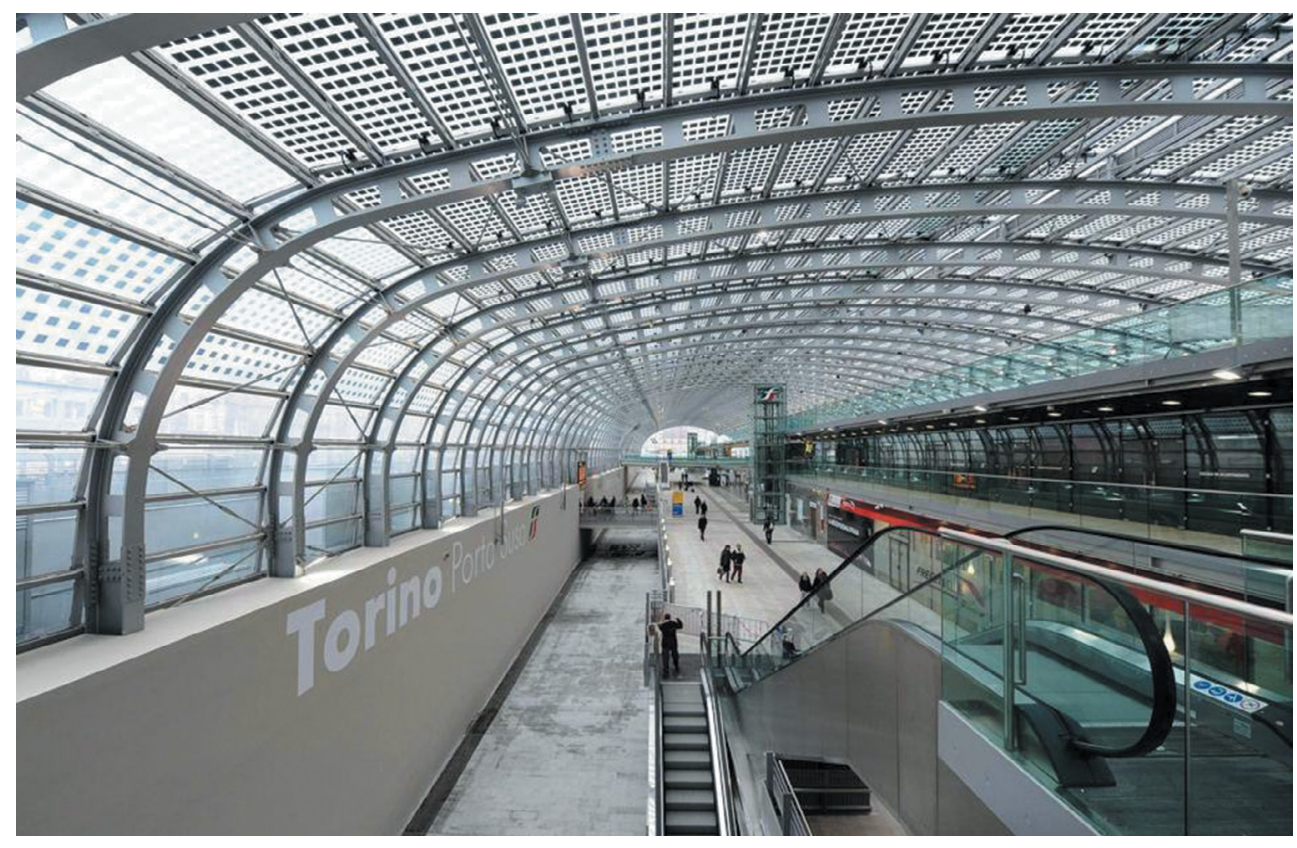

Figure 5: Torino Porta Susa, view of the ground level. (Ansa/Di Marco) 
regeneration, the 'Spina Centrale' ('backbone') aimed to reconnect two sectors of the city that had been separated by the railway track for a century and a half, led to the final burial of over 7 kilometres of track.

The exterior of the station, built near the old passengers' building, is a winding glass arcade extending a length of 385 metres. The construction is supported by 108 steel arches of varying height which follow the profile of the arcade. The glass ceiling is integrated with $15,000 \mathrm{~m}^{2}$ of solar panels.

The first floor of the building - located some metres below the road - is articulated in a long corridor onto the exterior side of which all service activities and commercial businesses face, while on the other side are the entrances to the transversal underground passages that lead to the tracks, located on the lower level. The entrance to the underground system is also found on the second floor. Descending a floor you reach the underground railway tracks (Fig. 6).

The Porta Susa station is also characterized by the sustainability of the technological and plant engineering solutions used. Thanks to the solar panels integrated in the glass arcade, which are able to generate $680,000 \mathrm{KWh} /$ year while at the same time giving shade to the inside of the building, the station was awarded the European Solar Prize 2012. Air conditioning is naturally sourced, taking advantage of the thermal gradient generated by the difference between the warm air of the arcade and the cooler air that comes from the floor below, where the tracks are. The hot air is expelled through special openings in the upper surface of the arcade. Moreover, a system of radiant panels helps modulate the heating and air conditioning of the interiors as required.

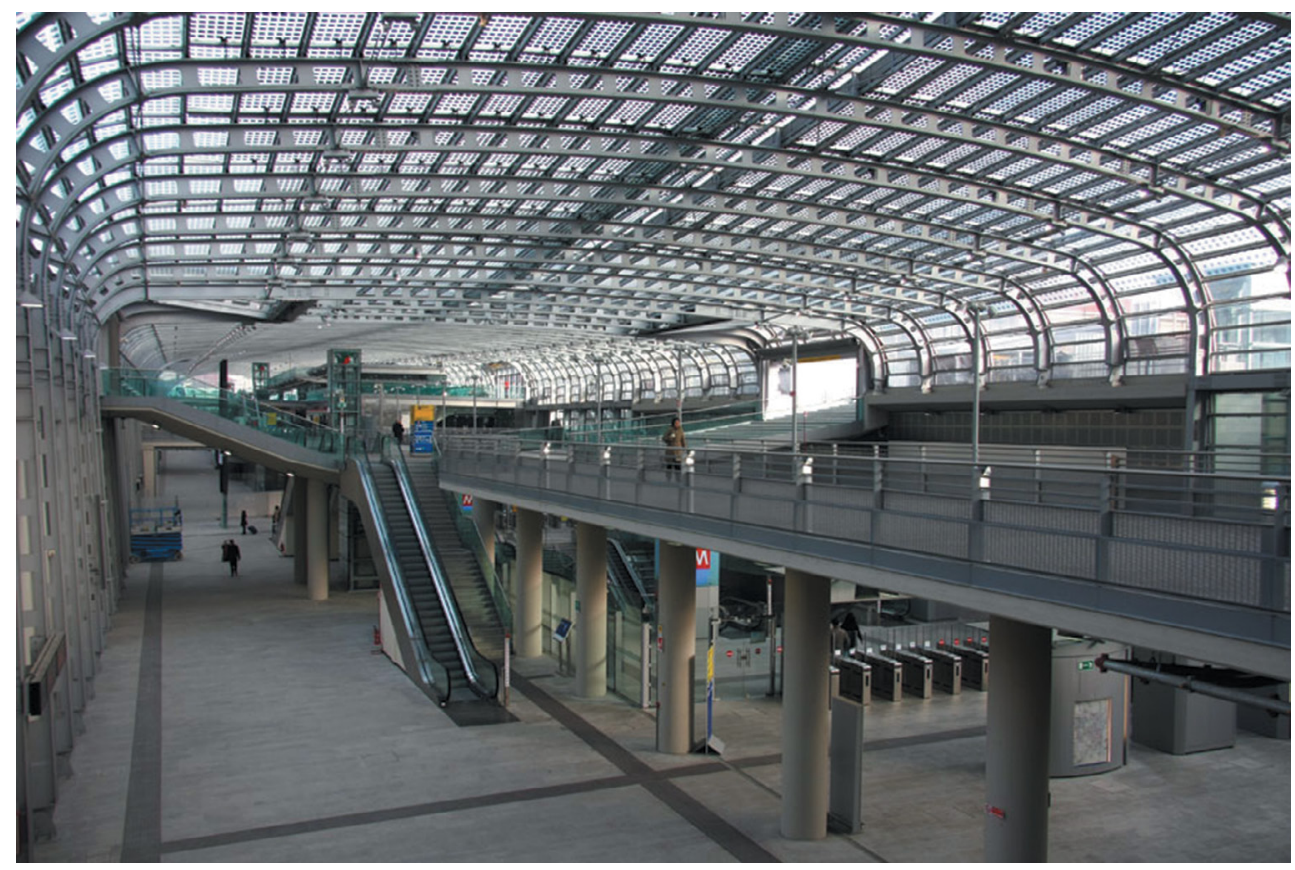

Figure 6: Torino Porta Susa, the connection between the ground floor and the entrance to the subway. (www.fsnews.it) 


\subsection{Adjustments made for the high speed service of Roma Tiburtina}

The Roma Tiburtina station is another example of a secondary station transformed for the passing of urban rail traffic and the high speed service and to be integrated with the underground services of the urban centre. The original station, originally named Portonaccio, was built at the end of the 19th century along the Roma-Orte line, just outside the urban centre. In the 1930s, they started considering the need for expansion, especially due to the universal exhibition planned for Rome in 1942. In March 1944, a large part of the station was damaged and destroyed in bombing and rebuilt in the post-war years partly on the plans drafted before the conflict and completed in 1949.

Being an important hub for the railway connections of the north-south axis, with the extension of the underground B Line that arrived nearby and with the intention to create the high speed and high capacity railway network, the Roma Tiburtina station became Rome's second most important one after Termini. Thus between the 1980s and the 1990s the need arose to modernize and adapt the station and surrounding area. The call for tenders of 1996 through the invited consultation of 13 renowned designers ended with the appointment of Renzo Piano who designed a passengers' building with a two-floor slab bridge above the tracks, the burial of the Tangenziale Est (East freeway) near the tracks, and four, 130-metre high twin turrets. Piano's project was not executed for a variety of reasons. In occasion of the 2000 Jubilee, a number of redevelopment operations were undertaken that are no longer extendable, but neither are they sufficient. In 2001, a further international bid for tenders was called for the design of the station and the surrounding areas which was won by Paolo Desideri's ABDR [8].

Here again, like that for Porta Susa in Turin, we find that the basic idea of the new organization of the station is to reunite two districts that historically had been divided by the railway the Pietralata and Nomentano districts - and to turn it into a strategic urban hub through the intersection with other forms of transport, specifically with the existing underground B Line, but also with other public transport services and the creation of both ground-floor and underground car parks on the Pietralata side of the station (Fig. 7).

The new station has 25 railway linked tracks, of which 17 serve for passenger transportation and two are branch lines. Above it is the grid structured ceiling built in 2000 that supports - as already planned in Renzo Piano's project - a 240-metre-long glass parallelepiped arcade located at nine metres above the road on the side of the entrance hall of the Nomentano district (Fig. 8).

The brace function of the structure is undertaken by the stairwells found on the far sides. Inside the arcade there are eight suspended volumes used for catering, entertainment and offices. The volumes are individually linked to the arcade by escalators and lifts, but also between them, through an aerial platform on the side.

From the energy aspect, the Roma Tiburtina station has been equipped with sustainable solutions integrated with traditional methods. The temperature in the arcade is in fact controlled by the sun both directly and indirectly. Moreover, the hot air produced during the summer through the greenhouse effect is used as a convector engine to expel the hot air itself and to allow cool air to pass, making a cycle system possible. Traditional systems have been implemented, however, for the inner interior areas, such as the suspended volumes and the commercial areas. 


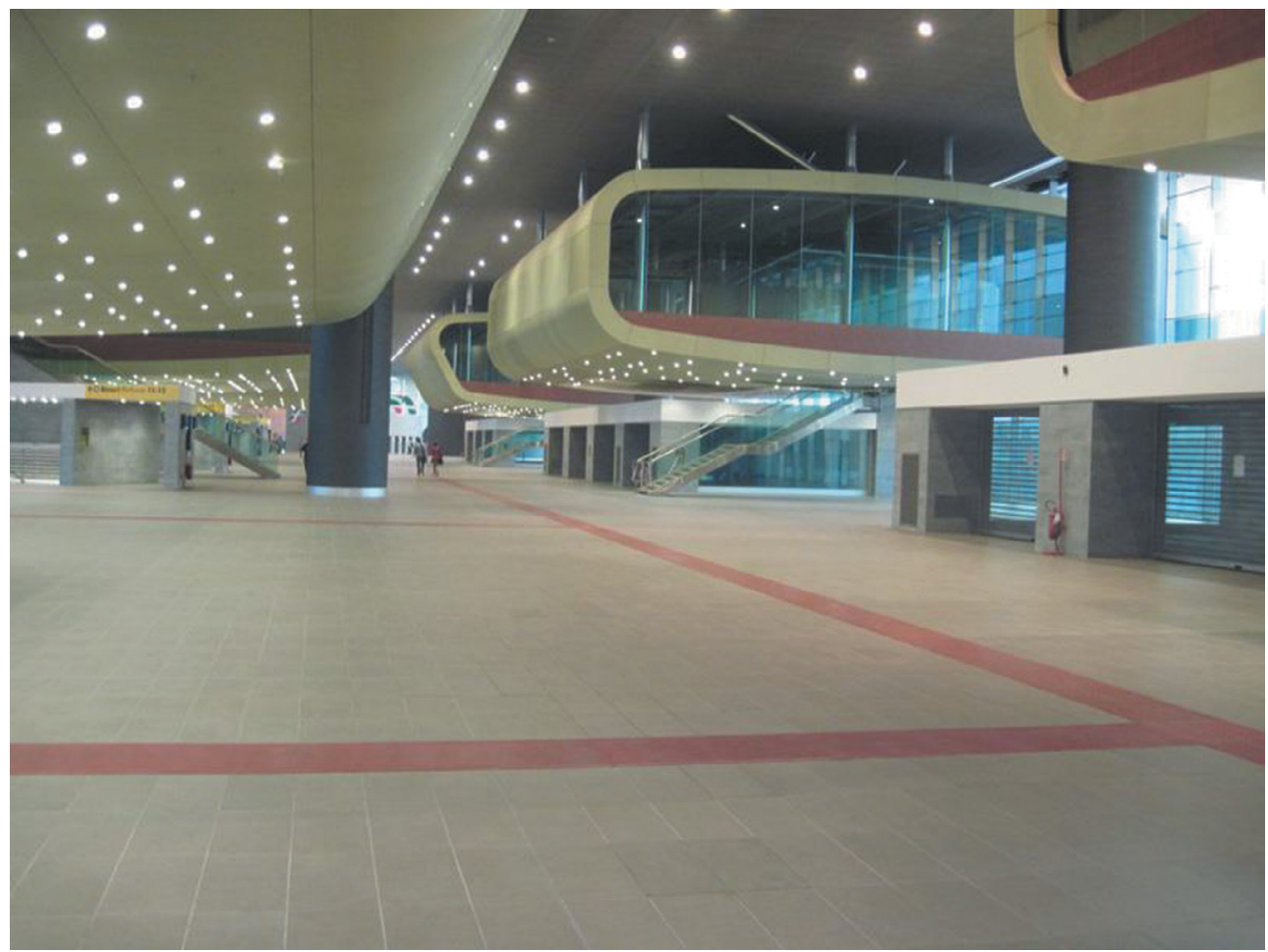

Figure 7: Roma Tiburtina, the suspended volumes inside the arcade used for catering, entertainment and offices. (www.arketipomagazine.it)

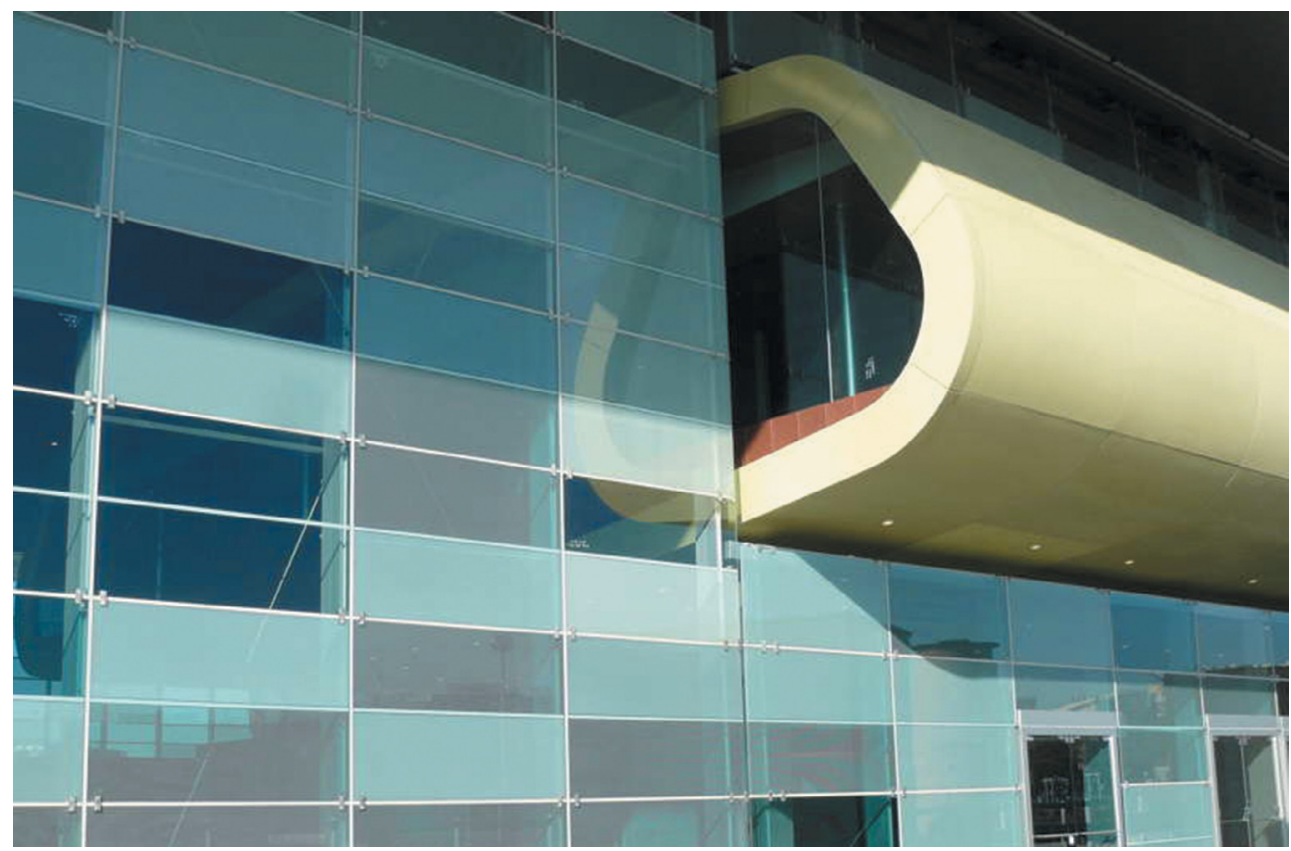

Figure 8: Roma Tiburtina, the glass building envelope. (www.arketipomagazine.it) 


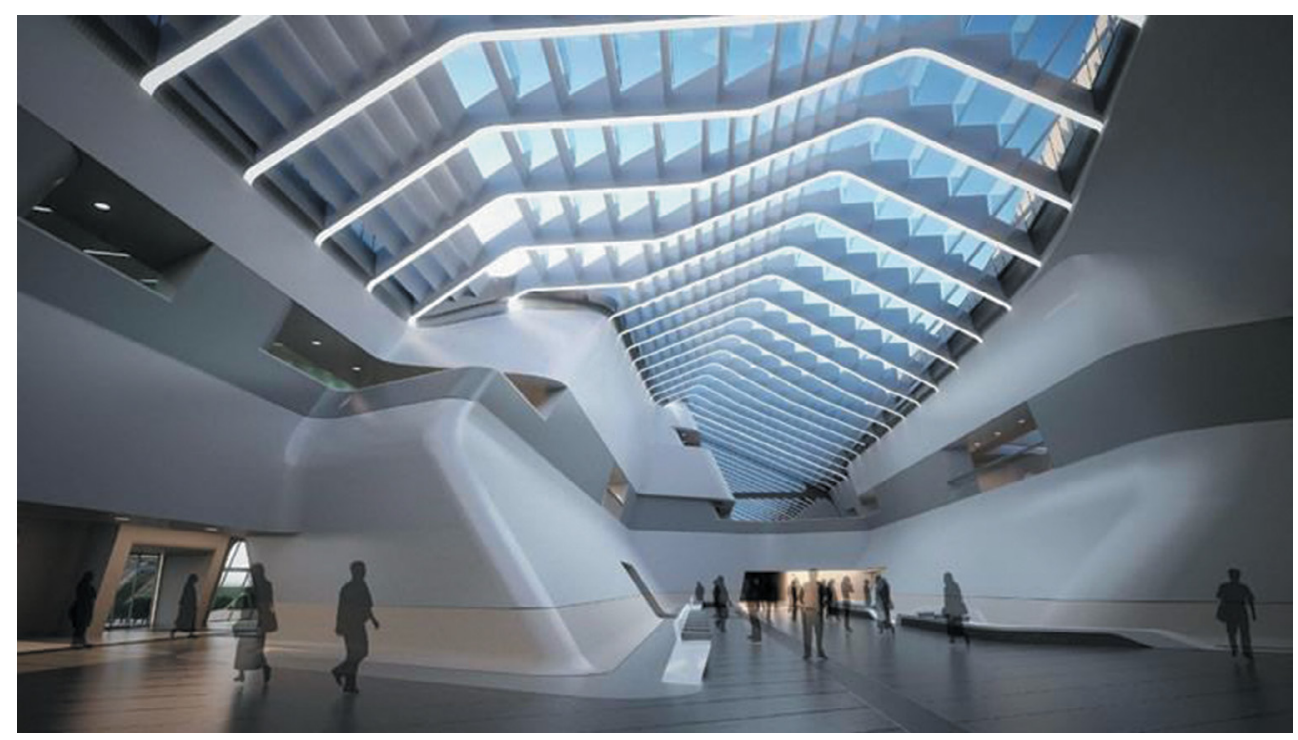

Figure 9: Napoli Afragola, the new high speed station. (Zaha Hadid Architects)

\section{CONCLUSIONS}

Over time, the railway station has been characterized as the most advanced product of the architectural and technical culture of the period in which it was constructed (Fig. 9). The methods of planning and building railway stations are therefore in continual evolution and are closely linked to the technical progress of the transport itself. Railway architecture therefore represents a rather fragile heritage, all considered, and must be closely studied to be protected correctly. In the current process of reconversion underway in a number of large stations, which today no longer represent the nerve centre of railway traffic, the players, constructive methods, technical knowledge and therefore the history of construction, must all be opportunely valorized to avoid being misinterpreted or lost forever.

\section{REFERENCES}

[1] Altarelli, L. et al., La stazione e la città. Gangemi: Roma, 1990.

[2] Godoli, G. \& Cozzi, M., (eds), Architettura ferroviaria in Italia, Ottocento. Flaccovio: Palermo, 2004.

[3] Ballatore, L. \& Masi, F., Torino Porta Nuova. Storia delle ferrovie piemontesi, Edizioni Abete: Roma, 1988.

[4] Angeleri, G. \& Columba, C., Milano Centrale: storia di una stazione, Edizioni Abete: Roma, 1985.

[5] Godoli, G. \& Rita, A.I., (eds), Architettura ferroviaria in Italia, Novecento. Flaccovio: Palermo, 2004.

[6] R.F.I. Spa \& T.A.V. Spa, Stazioni. Luoghi per le città, Mondadori-Electa: Milano, 2004.

[7] R.F.I. Spa, Il nodo urbano. Il concorso della nuova stazione di Torino Porta Susa, Arca Edizioni: Milano, 2003.

[8] ABDR Architetti Associati, High Speed station - Roma Tiburtina, Italy. Arketipo, 50, pp. 102-113, 2011. 